\title{
Grossi, Paolo, Mitologie giuridiche della modernità (Giuffrè, Milán, 2007, pp. 234) y Europa y el Derecho (trad. L. Guiliani, Crítica, Barcelona, 2007, 235 pp.).
}

Paolo Grossi (Florencia, 1933) no necesita de mayores presentaciones en el mundo hispanoamericano. El profesor de Historia del Derecho de la Universidad de Florencia y miembro de la Accademia Nazionale dei Lincei es uno de los más prestigiosos historiadores y formadores de la llamada Escuela florentina de la historia del Derecho. Entre sus obras traducidas al castellano destacan Historia del derecho de propiedad: la irrupción del colectivismo en la conciencia europea (Ariel, Barcelona, 1986); La propiedad y las propiedades: un análisis histórico (Civitas, Madrid, 1992); El orden jurídico medieval (trad. F. Tompas y Valiente y C. Álvarez, Marcial Pons, Madrid, 1996); Mitología jurídica de la modernidad (trad. M. Martínez Neira, Trotta, Madrid, 2003); la colección de trabajos titulada Derecho, sociedad, Estado. Una recuperación para el Derecho (Escuela Libre de Derecho, El Colegio de Michoacán, Universidad Michoacana de San Nicolás de Hidalgo, México, 2005) y, más recientemente, La primera lección de Derecho (trad. C. Alonso, Marcial Pons, Madrid, 2006). Del resto, son relevantes Assolutismo giuridico e diritto privato (Giuffrè, Milán, 1998), como también Scienza giuridica italiana. Un profilo storico (1860-1950), Giuffrè, Milán, 2000).

Mitologie giuridiche della modernità es la tercera edición del libro que el año 2003 viera la luz en castellano, desde las prensas de la editorial madrileña Trotta. El texto reúne varias conferencias sobre temas que, con frecuencia a lo largo de su obra, han llamado la atención del autor: (I) "La justicia como ley o la ley como justicia", (II) "Más allá de las mitologías jurídicas de la modernidad", (III) "Códigos: algunas conclusiones entre un milenio y el otro", (IV) "Las variadas vidas del jacobinismo jurídico o 'La Carta de Niza', el proyecto de 'Constitución europea' y las insatisfacciones de un historiador del Derecho" y, por último, (V) "El constitucionalismo moderno entre mito e historia". Los tres primeros textos habían sido comprendidos en ediciones anteriores, mientras que los dos últimos son un privilegio de la última edición italiana.

Europa y el Derecho forma parte de la notable colección "La construcción de Europa" dirigida por J. Le Goff y materializada por las editoriales europeas C. H. Beck (Munich), Basil Blackwell (Oxford), Crítica (Barcelona), Laterza (Roma-Bari) y Éditions du Seuil (Paris). El texto persigue el ambicioso objeto de "esbozar los rasgos esenciales de un itinerario histórico-jurídico que abarca más de mil quinientos años y presenta una dimensión europea" en un libro al alcance de los menos expertos en la 
historia del Derecho europeo. La gran experiencia del autor, dueño de un estilo claro y preciso, hace que el objetivo se cumpla con creces y que el libro que reseñamos se convierta en un texto valiosísimo para los estudiantes latinoamericanos. Quizá no por casualidad, el A. haya dedicado el libro a sus discípulos brasileños y mexicanos.

Ambos libros se encuentran hilvanados por una desafiante visión de la función del historiador del Derecho. Para el A. -que no tiene reparos en confesar que es una afirmación que repite hasta "parecer monótono" (Mitologie, pág. 3) - la misión del historiador del Derecho es criticar y desmitificar las visiones modernas del Derecho desde la perspectiva del pasado y de la comparación. Desde ese punto de vista, el historiador es "una garantía del futuro" (Mitologie, 39), de un futuro que "siempre tiene un rostro antiguo" (Mitologie, 89). Por eso, este libro es un buen comienzo para desprenderse de una buena parte de las certezas o dogmas del Derecho contemporáneo.

Para liberarse de los prejuicios ideológico-jurídicos de la modernidad, y comprender (y recuperar) la juridicidad más allá del Estado, es preciso recorrer la historia de Europa antes del surgimiento del Estado moderno. Para ello resulta fundamental detenerse en la estructura pluralista del orden medieval ${ }^{1}$, que ofrece una juridicidad desencadenada del poder político soberano y, por lo tanto, más cercana a las comunidades donde se desenvuelven los conflictos que el Derecho pretende resolver. Este "rostro antiguo" es, precisamente, el que permite comprender la actual y progresiva descomposición del "orden" estatal (piramidal, hermético, sin lagunas, coherente) en favor de un orden pluralista y no estatalista ${ }^{2}$. En este sentido, la reflexión del orden medieval (vid. Europa y el Derecho, pp. 19-60), donde la falta de un Estado soberano torna en irremediablemente incompleto el poder político, permite derribar buena parte de los mitos jurídicos de la modernidad, mitos que, al igual que las gafas que ponemos ante nuestros ojos, deforman y condicionan la percepción de la realidad (Mitologie, 63).

En defensa del pluralismo el A. recuerda una visión medieval del orden -esse unum secundum ordinem, non est esse unum simpliciter, en la expresión de Sto. Tomás- que trae inmediatamente a la memoria el nuevo motto de la Unión Europea: unida en la diversidad. De allí que en la última edición de las Mitologie no escape a la crítica histórica la Carta de Derechos de la Unión Europea, proclamada en Niza el año 2000. Como se

Véase, con más profundidad, el libro L'ordine giuridico medievale ( $8^{\mathrm{a}}$ ed., Laterza, Roma-Bari, 2001).

Vid. del mismo Grossi, "Globalizzazione e pluralismo giuridico", Quaderni Fiorentini 29 (2000), pp. 551-558. 
sabe, esta Carta prolonga, en pleno siglo XXI, el espíritu codificador del racionalismo del siglo XVIII y la desconfianza hacia los jueces (expresada en una fragmento del Espíritu de las Leyes de Montesquieu que ha sido repetido hasta la saciedad en la literatura constitucional). La naturaleza de la Carta, como símbolo o documento de catecismo (en el decir de Santi Romano, según lo recuerda el propio A., Mitologie, 147) queda entonces en evidencia, y así lo confirman otras interpretaciones. Entre estas últimas cabe mencionar la explicación de una tendencia que viene reforzándose desde principios de los años noventa, y que ha sido descrita por J. Habermas como la expresión de "una nueva conciencia de comunidad" 3 . O como escribe J. H. H. WeIler: "la Carta, como símbolo importante, contrapesaría al euro y se convertiría en parte de la iconografía de la integración europea, contribuyendo tanto a la identidad como a la identificación con Europa" 4 .

El análisis mítico del Derecho en general, y del constitucionalismo en particular, no es nuevo. Varias premisas del constitucionalismo moderno (estado de naturaleza, contrato social, voluntad general, etc.) fueron comprendidas dentro de la categoría de "mito jurídico" en el análisis clásico de Santi Romano: Frammenti di un Dizionario Giuridico (Giuffrè, Milano, 1953), pp. 130 y ss. Más recientemente, este análisis mitológico del constitucionalismo ha sido desarrollado con profundidad en Portugal por Da Cunha, Paulo Ferreira: Mito e Constitucionalismo (perspectiva conceptual e histórica) (Separata del vol. XXXIII del Suplemento ao Boletim da Facultade de Dereito da Universidade de Coimbra, Coimbra, 1990) y Pensar o Dereito. Vol. I. Do realismo clássico à análise mítica (Livraria Almedina, Coimbra, 1990, pp. 343 y ss.).

El significado de este análisis mitológico de una noción aparentemente muy lejana de la mitología es explicado por el A., como es natural, desde la perspectiva del historiador. Desde esa trinchera, Grossi denuncia a la modernidad como una gran constructora de mitos (Mitologie, 45 y ss.) y pseudoverdades (196 y ss.), falacias que han calado profundo en nuestra formación de juristas y, desde allí, en nuestra manera de concebir el Derecho. Si el aprendiz de jurista desea dudar de aquellas concepciones imperativistas del Derecho (centradas en el acto potestativo de la norma), de la unidad y coherencia de los ordenamientos jurídicos estatales y de la centralidad del Estado para la producción del Derecho, no puede hacer mejor cosa que leer este libro con urgencia. Si, en cambio, prefiere contentarse

So, Why Does Europe Need a Constitution? (trad. M. Everson, European University InstituteRobert Schuman Centre of Advanced Studies, Florence, 2001), p. 23.

4 Weiler, Joseph: "Human Rights, Constitutionalism and Integration: Iconography and Fetishism", International Law Forum du droit international 3 (2001), p. 232. 
con las certezas que brindan los conceptos de seguridad, legalidad, orden piramidal, soberanía, codificación y poder constituyente, hará bien en no abrirlo.

Manuel A. Núñez Poblete*

Profesor de Derecho Constitucional de la Universidad Católica del Norte (Chile). Doctor en Derecho de la Universidad Santiago de Compostela (España). Correo electrónico: manunez@ ucn.cl 